\title{
A History of Ischemic Heart Disease is a Common Cause of Wheezing in the Elderly of a Japanese Local Community
}

\author{
Minehiko Inomata ${ }^{1}$, Yukio Kawagishi ${ }^{1,2}$, Kotaro Tokui ${ }^{1}$, Yasuaki Masaki ${ }^{1}$, Chihiro Taka ${ }^{1}$, \\ Kenta Kambara ${ }^{1}$, Seisuke Okazawa ${ }^{1}$, Shingo Imanishi ${ }^{1}$, Tomomi Ichikawa ${ }^{1}$, \\ Kensuke Suzuki ${ }^{1}$, Toru Yamada ${ }^{1}$, Minoru Iwata ${ }^{1}$, Isao Usui ${ }^{1}$, Shigeki Sumi ${ }^{3,4}$, \\ Hideki Origasa ${ }^{4}$, Shoko Matsui ${ }^{5}$, Ryuji Hayashi ${ }^{1}$ and Kazuyuki Tobe ${ }^{1}$
}

\begin{abstract}
Objective We conducted a cross-sectional study to investigate which factors have a significant impact on wheezing and QOL in the elderly of a Japanese local community.

Methods In 2008, 527 participants (250 participants aged 45 to 64 years and 277 participants aged 65 to 88 years) responded to the questionnaire regarding wheezing and disease history. QOL was evaluated by the Short Form-8. The participants underwent airway reversibility testing. The plasma levels of IgE were measured. The plasma levels of N-terminal-pro-B-type natriuretic peptide were measured in twenty-one participants with a history of ischemic heart disease and in thirty-five age-matched participants without that history. Results Wheezing was reported by $50(9.5 \%)$ participants and was associated with a lower score of QOL. In multivariate analysis, wheezing was associated with sex (OR 3.12, CI 1.10-9.67) and a history of bronchial asthma (OR 22.3, CI 6.50-84.0) among participants aged 45 to 64 years. Among participants aged 65 and over, wheezing was associated with a history of bronchial asthma (OR 4.86, CI 1.39-15.1) and ischemic heart disease (OR 5.12, CI 1.61-15.0). Participants with both a history of ischemic heart disease and wheezing showed higher levels of N-terminal-pro-B-type natriuretic peptide. Airway reversibility was only associated with a history of ischemic heart disease (OR 4.65, CI 1.26-17.6).

Conclusion It is suggested that bronchial asthma and heart disease are both significant causes of wheezing and affect the QOL in the elderly of a Japanese local community.
\end{abstract}

Key words: wheezing, elderly, ischemic heart disease, asthma, airway reversibility

(Intern Med 50: 2975-2981, 2011)

(DOI: 10.2169/internalmedicine.50.6201)

\section{Introduction}

Asthma is a common disease and the number of asthmatic patients is estimated about 300 million and still increasing all over the world (1). Recently, therapeutic advances in asthma management, such as the use of inhaled corticosteroids, have not only resulted in improvement in the asthma symptoms in most patients, but also brought about a decrease in asthma deaths $(2,3)$. However, asthma in the eld- erly (65 years or over) is more problematic because of its diagnostic issues and mortality $(4,5)$.

Wheezing is a primary symptom of bronchial asthma and is the most sensitive question for asthma survey (6). However, most studies showed that the prevalence of wheezing was almost twice or more than that of defined asthma $(6,7)$. Recently, a Japanese nationwide study, in which we participated, revealed the asthmatic and wheezing prevalence in Japan (8). That study also showed that the prevalence of wheezing was almost twice that of asthmatics. However, the

\footnotetext{
${ }^{1}$ The First Department of Internal Medicine, University of Toyama, Japan, ${ }^{2}$ Internal Medicine, Kurobe City Hospital, Japan, ${ }^{3}$ Center for the Advancement of Medical Training, University Hospital of Toyama, Japan, ${ }^{4}$ Division of Biostatistics and Clinical Epidemiology, University of Toyama, Japan and ${ }^{5}$ Health Administration Center, University of Toyama, Japan Received for publication July 17, 2011; Accepted for publication September 8, 2011 Correspondence to Dr. Ryuji Hayashi, htaro@med.u-toyama.ac.jp
} 
causes of wheezing other than asthma have rarely been studied in a population-based study.

Asthma-related symptoms such as wheezing are significantly associated with the quality of life (QOL) (9). Therefore, the precise diagnosis of wheezing and proper treatment of individuals with wheezing is important for the affected people.

Wheezing in the elderly may be the manifestation of various diseases other than asthma, such as chronic obstructive pulmonary disease (COPD), congestive heart failure, pulmonary aspiration, and lung cancer (10). COPD is one of the most frequent causes of respiratory illness in the elderly and its symptoms resemble asthma (11). Another important disease that manifests similar symptoms as asthma is heart disease (12). Because heart disease is also prevalent in the elderly, it is more difficult to conduct an asthma survey based on asthmatic symptoms.

It is important to elucidate wheezing prevalence and the causes of wheezing in elderly individuals because the aging society is growing and wheezing itself can be a cause of decreased QOL. The aim of this cross-sectional study was to evaluate the prevalence of wheezing and the association between wheezing and QOL, and to elucidate the etiology of wheezing in the elderly population aged 65 years or over compared with a middle-aged population aged 45 to 64 years in a Japanese local community.

\section{Materials and Methods}

\section{The subjects of investigation}

This study was performed in Jinbo, a town of Toyama city with a population of 5,007 including 2,465 people aged 45 years old or over. All of the subjects aged 45 years old or over were invited to participate in the study at regional community centers and 527 of them $(21.4 \%)$ responded to the invitation and completed the questionnaire. We divided participants into two categories according to age: 45 to 64 , middle aged $(n=250)$, and 65 to 88 , elderly $(n=277)$. The study was conducted with the approval of the Ethics Committee of the University of Toyama (Ethics Committee, University of Toyama), and all participants were assured that their personal health information would be kept confidential and secure.

\section{Questionnaire}

We asked the participants to complete the questionnaire regarding wheezing, smoking status, and a history of bronchial asthma, ischemic heart disease, and allergic rhinitis. Wheezing was assessed by asking "Have you had wheezing or whistling in your chest at any time in the last twelve months?"

QOL was evaluated by the Short Form-8 (SF-8). The SF8 is an abbreviated form of the Short Form-36 that is used for large-scale health measurements (13). The physical component summary (PCS) and mental component summary
(MCS) scores were calculated; higher scores indicated a higher-quality health status.

\section{Lung function test}

Spirometry was completed as recommended by the American Thoracic Society/European Respiratory Society (14). All participants underwent baseline lung function testing and repeated the required maneuvers three times while wearing nose clips. The highest of the three measured $\mathrm{FEV}_{1}$ values was used for the analysis. Salbutamol was administered by inhalation through a spacer device at a dose of $200 \mu \mathrm{g}$, and the test was repeated 30 minutes later. Subjects who were 86 years or older, had hyperthyroidism, extraordinary hypertension (systolic blood pressure $>180$ $\mathrm{mmHg}$, diastolic blood pressure $>100 \mathrm{mmHg}$ ), tachycardia, active angina pectoris, active congestive heart failure, anxiety and were considered not to be appropriate for salbutamol inhalation, as assessed by examining doctors, were excluded from the bronchodilator test. Seventy of the 527 subjects $(13.3 \%)$ were excluded by the exclusion criteria. Therefore, 457 subjects underwent the bronchodilator test. An increase in the $\mathrm{FEV}_{1}$ by $12 \%$ of baseline and $0.2 \mathrm{~L}$ was considered to represent significant airway reversibility. Participants with an $\mathrm{FEV}_{1} / \mathrm{FVC}$ ratio $<0.7$ were diagnosed with airflow limitation.

\section{IgE and NT-pro-BNP measurement}

The plasma levels of total non-specific IgE and allergenspecific IgE (measured by a radioallergosorbent test, or RAST) were measured for all participants. The plasma level of creatinine and N-terminal-pro-B-type natriuretic peptide (NT-pro-BNP) levels in participants with a history of ischemic heart disease $(n=21)$ and in some of the participants with no history of ischemic heart disease $(n=35)$ were measured.

\section{Statistical analysis}

Data are presented as the mean (SD) unless otherwise indicated. Analyses were performed using a statistical software package (JMP, version 9.0.0). Fisher's exact test was used to compare categorical variables, and Student's t test and Wilcoxon's rank sum test were used to compare numerical variables. Multiple regression analyses were used to assess the association between the QOL scores, lung function, and wheezing. A logistic regression analysis was used to identify the independent risk factors for wheezing and airway reversibility in the middle-aged and elderly participants. The plasma levels of NT-pro-BNP in groups were compared by analysis of variance (ANOVA) followed by a Tukey's test. A $p$ value of $<0.05$ was considered to be statistically significant.

\section{Results}

Table 1 shows participant characteristics. The survey questionnaire was completed by 527 participants. The mean 
Table 1. Demographic Characteristics and Disease History According to

Age

\begin{tabular}{lcccc}
\hline $\begin{array}{l}\text { Age } \\
\begin{array}{l}\text { Number of } \\
\text { participants }\end{array}\end{array}$ & Whole & $45-64$ & $65-88$ & $\mathrm{p}$ \\
\hline Men & $219(41.6 \%)$ & $98(39.2 \%)$ & $121(43.7 \%)$ & 0.33 \\
$\begin{array}{l}\text { Smoking history } \\
\begin{array}{l}\text { History of bronchial } \\
\text { asthma }\end{array}\end{array}$ & $156(29.6 \%)$ & $94(37.6 \%)$ & $62(22.4 \%)$ & 0.0002 \\
$\begin{array}{l}\text { History of allergic } \\
\text { hinitis }\end{array}$ & $120(22.8 \%)$ & $74(29.6 \%)$ & $46(16.6 \%)$ & 0.0004 \\
$\begin{array}{l}\text { History of ischemic } \\
\text { heart disease }\end{array}$ & $21(4.0 \%)$ & $2(0.8 \%)$ & $19(6.9 \%)$ & 0.0002 \\
\begin{tabular}{l} 
Wheezing \\
\hline
\end{tabular} & $50(9.5 \%)$ & $21(8.4 \%)$ & $29(10.5 \%)$ & 0.46 \\
\hline
\end{tabular}

Table 2. Results of Baseline Lung Function Testing, Airway Reversibility Testing, and IgE Measurements

\begin{tabular}{|c|c|c|c|c|}
\hline Age & Whole & $45-64$ & $65-88$ & $\mathrm{p}$ \\
\hline Number of participants & 527 & 250 & 277 & \\
\hline Base line $\mathrm{FEV}_{1} \%$ pred. & $96.5(22.0)$ & $95.9(21.4)$ & $97.1(22.5)$ & 0.53 \\
\hline $\begin{array}{l}\text { Post-bronchodilator } \\
\text { FEV }_{1} \% \text { pred. }\end{array}$ & $105.0(20.0)$ & $104.0(18.6)$ & $105.8(21.2)$ & 0.34 \\
\hline $\begin{array}{l}\text { base line airflow } \\
\text { limitation }\end{array}$ & $63(12.0 \%)$ & $21(8.4 \%)$ & $42(15.2 \%)$ & 0.022 \\
\hline $\begin{array}{l}\text { Post-bronchodilator } \\
\text { airflow limitation }\end{array}$ & $44(9.6 \%)$ & $18(8.1 \%)$ & $26(11.1 \%)$ & 0.34 \\
\hline Airway reversibility ${ }^{*}$ & $89(19.5 \%)$ & $38(17.0 \%)$ & $51(21.8 \%)$ & 0.24 \\
\hline Total $\operatorname{IgE}(\mathrm{IU} / \mathrm{mL})^{\dagger}$ & $55(21-168)$ & $63(21.8-198.3)$ & $48(20-159)$ & 0.22 \\
\hline Cedar pollen ${ }^{\S}$ & $113(21.4 \%)$ & $81(32.4 \%)$ & $32(11.6 \%)$ & $<0.0001$ \\
\hline House dust ${ }^{\S}$ & $76(14.4 \%)$ & $50(20.0 \%)$ & $26(9.4 \%)$ & 0.0007 \\
\hline
\end{tabular}

age of all participants was 64.9 (SD 9.5, range 45 to 88 years old) and $41.6 \%$ of them was men. We divided participants into two categories according to age: 45 to 64 , middle aged, and 65 to 88 , elderly. We compared the wheezing prevalence and other associated factors of the two groups. Histories of ischemic heart disease were reported more frequently in participants aged 65 to 88 years, and histories of allergic rhinitis were reported more frequently in participants aged 45 to 64 years. Wheezing was reported in fifty $(9.5 \%)$ participants and we found no significant difference of frequency of wheezing between each group.

Table 2 shows lung function testing and $\operatorname{IgE}$ measurement results. Sixty three $(12.0 \%$ of whole participants) participants showed pre-bronchodilator airflow limitation. Airway reversibility testing was completed in 457 participants. The mean change of $\mathrm{FEV}_{1}$ after inhalation of the bronchodilator $\left(\triangle \mathrm{FEV}_{1}\right)$ was $97.2 \mathrm{~mL}$, and its relative change was $5.4 \%$. Eighty-nine $(19.5 \%$ of participants who underwent reversi- bility testing) participants showed airway reversibility and forty-four participants $(9.6 \%$ of participants who underwent reversibility testing) showed post-bronchodilator airflow limitation. Allergen-specific IgE was detected more frequently in the younger participant group.

Table 3 shows the association between wheezing or lung functions and SF-8 scores. Participants with wheezing showed significantly lower PCS scores after adjusting for age, sex, and past histories. However, airflow limitation and airway reversibility were not associated with the QOL score.

In the participants aged 45 to 64 years, sex (men, OR 3.45 , 95\%CI 1.34-8.89, $\mathrm{p}=0.0096$ ), a history of bronchial asthma (OR 27.88, 95\% CI 8.52-91.18, p<0.0001), and allergic rhinitis (OR 2.90, 95\% CI 1.17-7.16, p=0.024) were identified as being significantly associated with wheezing in the univariate analysis. However, other factors such as airway reversibility (OR $0.52,95 \%$ CI $0.11-2.32$, p=0.54), pre(OR $1.16,95 \%$ CI $0.25-5.38, \mathrm{p}=0.69$ ) or post-bronchodilator 
Table 3. Association between SF-8 Scores and Wheezing or Lung Function

\begin{tabular}{|c|c|c|c|c|c|}
\hline & & PCS & $\mathrm{p}$ & MCS & $\mathrm{p}$ \\
\hline \multirow[t]{2}{*}{ Wheezing } & $(+) n=50$ & $45.9(6.8)$ & 0.027 & $48.2(6.8)$ & 0.090 \\
\hline & $(-) n=477$ & $48.5(6.0)$ & & $50.3(5.5)$ & \\
\hline \multirow[t]{2}{*}{ Airway reversibility } & $(+) n=89$ & $48.0(6.9)$ & 0.56 & $50.2(5.6)$ & 0.63 \\
\hline & $(-) n=368$ & $48.7(5.7)$ & & $50.2(5.8)$ & \\
\hline \multirow[t]{2}{*}{$\begin{array}{l}\text { Pre-bronchodilator } \\
\text { airflow limitation }\end{array}$} & $(+) n=63$ & $46.6(7.1)$ & 0.16 & $49.0(5.7)$ & 0.16 \\
\hline & $(-) n=464$ & $48.4(5.9)$ & & $48.5(6.0)$ & \\
\hline \multirow[t]{2}{*}{$\begin{array}{l}\text { Post-bronchodilator } \\
\text { airflow limitation }\end{array}$} & $(+) n=44$ & $49.0(6.6)$ & 0.28 & $49.5(7.3)$ & 0.34 \\
\hline & $(-) n=413$ & $50.3(5.5)$ & & $50.3(5.5)$ & \\
\hline
\end{tabular}

Table 4. Multivariate Analyses to Assess the Relationship between Wheezing and a History of Diseases among According to Age

\begin{tabular}{|c|c|c|c|c|c|c|c|}
\hline \multicolumn{4}{|c|}{45 to 64 years $(n=250)$} & \multicolumn{4}{|c|}{65 to 88 years $(n=277)$} \\
\hline Variables & OR & $95 \% \mathrm{CI}$ & $\mathrm{p}$ & Variables & OR & $95 \% \mathrm{CI}$ & $\mathrm{p}$ \\
\hline Age & 1.08 & $0.97-1.21$ & 0.17 & Age & 1.00 & $0.92-1.07$ & 0.92 \\
\hline Men & 3.12 & $1.10-9.67$ & 0.033 & Men & 0.88 & $0.38-1.97$ & 0.75 \\
\hline $\begin{array}{l}\text { Bronchial } \\
\text { asthma }\end{array}$ & 22.32 & $6.50-84.0$ & $<0.0001$ & $\begin{array}{l}\text { Bronchial } \\
\text { asthma }\end{array}$ & 4.86 & $1.39-15.1$ & 0.015 \\
\hline $\begin{array}{l}\text { Allergic } \\
\text { rhinitis }\end{array}$ & 2.41 & $0.80-7.13$ & 0.12 & $\begin{array}{l}\text { Ischemic } \\
\text { heart } \\
\text { disease }\end{array}$ & 5.12 & $1.61-15.0$ & 0.0070 \\
\hline
\end{tabular}

Definition of abbreviations: $\mathrm{OR}=$ odds ratio; $\mathrm{CI}=$ confidence interval

airflow limitation (OR 0.58, 95\% CI 0.07-4.57, p=1.00), smoking history (OR 1.93, 95\% CI 0.79-4.75, $\mathrm{p}=0.16$ ), plasma IgE (OR 1.00, 95\% CI 0.85-1.10, per $100 \mu / \mathrm{mL}$ increase, $\mathrm{p}=0.94$ ), cedar-pollen RAST value (OR 0.46, 95\% CI $0.15-1.43, \mathrm{p}=0.23$ ), or house-dust RAST value (OR 1.68, 95\% CI 0.62-4.58, p=0.39) were not associated with wheezing. We could not calculate the odds ratio between a history of ischemic heart disease and wheezing because two participants with a history of ischemic heart disease did not report wheezing.

In the participants aged 65 to 88 years old, a history of bronchial asthma (OR 4.49, 95\% CI 1.44-14.00, p=0.017) and ischemic heart disease (OR 4.72, 95\% CI 1.64-13.58, $\mathrm{p}=0.0081$ ) were identified as being significantly associated with wheezing in the univariate analysis. However, other factors such as sex (men, OR $0.9095 \% \mathrm{CI} 0.41-1.96$, $\mathrm{p}=$ 0.85 ), allergic rhinitis (OR 1.36, 95\%CI 0.52-3.54, $\mathrm{p}=0.60)$, airway reversibility (OR $0.89,95 \%$ CI $0.28-2.78, \mathrm{p}=1.00$ ), pre-bronchodilator airflow limitation (OR 2.40, 95\% CI $0.98-5.84, \mathrm{p}=0.058$ ), smoking history (OR 1.66, 95\% CI $0.71-3.85, \mathrm{p}=0.24)$, plasma IgE (OR 0.96 , 95\% CI $0.80-$
1.05, per $100 \mu / \mathrm{mL}$ increase, $\mathrm{p}=0.58$ ), cedar-pollen RAST value (OR $0.25,95 \%$ CI $0.03-1.90, \mathrm{p}=0.22$ ), or house-dust RAST value (OR 1.64, 95\% CI 0.52-5.15, p=0.33) was not associated with wheezing.

Table 4 shows the multivariate analyses to detect the factors which associate with wheezing in each group divided by age. In the participants aged 45 to 64 years, wheezing was associated with sex (men, OR 3.12, 95\%CI 1.10-9.67, $\mathrm{p}=0.0033$ ) and the history of bronchial asthma (OR 22.32, $95 \%$ CI $6.50-83.96, \mathrm{p}<0.0001)$. In the participants aged 65 to 88 , wheezing was associated with the history of bronchial asthma (OR 4.86, 95\%CI 1.39-15.13, p=0.015) and the history of ischemic heart disease (OR 5.12, 95\% CI 1.61-14.97, $\mathrm{p}=0.0070$ ).

We measured the plasma NT-pro-BNP levels in twentyone participants with a history of ischemic heart disease (aged 60 to 84 years) and in thirty-five age matched participants with no history of ischemic heart disease (aged 60 to 86 years) in order to evaluate the association between wheezing and heart disease. Participants with both a history of ischemic heart disease and wheezing showed significantly 


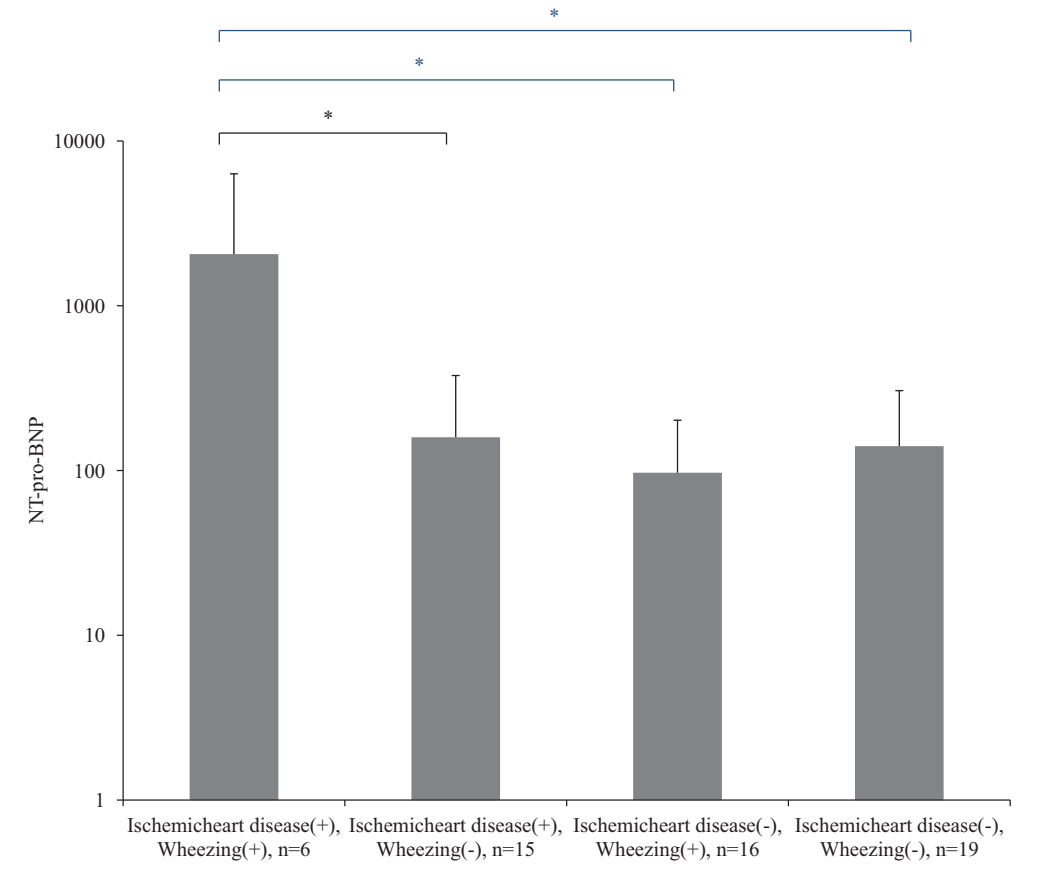

Figure 1. Plasma NT-pro-BNP levels in the twenty-one participants with a history of ischemic heart disease and the age-matched thirty-five participants without a history of ischemic heart disease. Those participants were classified into four categories based on the presence of ischemic heart disease and/or wheezing. $\mathrm{p}=\mathbf{0 . 0 0 6 5}$, ANOVA. *p<0.05, Tukey's test.

Table 5. Multivariate Analyses to Assess the Relationship between Airway Reversibility and a History of Diseases

\begin{tabular}{lccc}
\hline Variables & OR & $95 \% \mathrm{CI}$ & $\mathrm{p}$ \\
\hline Age & 1.00 & $0.97-1.02$ & 0.91 \\
Men & 1.14 & $0.69-1.85$ & 0.61 \\
$\begin{array}{l}\text { Pre-bronchodilator airflow } \\
\text { limitation }\end{array}$ & 4.58 & $2.50-8.39$ & $<0.0001$ \\
$\begin{array}{l}\text { Ischemic heart disease } \\
\text { Definition of abbreviations: OR = odds ratio; } \mathrm{CI}=\text { confidence interval }\end{array}$
\end{tabular}

higher plasma levels of NT-pro-BNP than the other three groups (Fig. 1).

In univariate analysis, we found no significant association between airway reversibility and wheezing (OR $0.71,95 \% \mathrm{CI}$ $0.29-1.75, \mathrm{p}=0.54$ ) or a history of asthma (OR 1.19, 95\%CI 0.47-3.05, $\mathrm{p}=0.80$ ). However, a history of ischemic heart disease (OR 5.25, 95\% CI 1.56-17.61, $\mathrm{p}=0.0093$ ), prebronchodilator airflow limitation (OR 4.65, 95\%CI 2.588.39, $\mathrm{p}<0.0001$ ) was associated with reversibility. In the multivariate analysis, pre-bronchodilator airflow limitation (OR 4.58, 95\%CI 2.50-8.39, p<0.0001) and a history of ischemic heart disease (OR 4.65, 95\% CI 1.26-17.62, $\mathrm{p}=$ 0.022 ) was found to be independently associated with airway reversibility (Table 5).

\section{Discussion}

The present study demonstrated that wheezing in the population aged 45 to 64 years was associated with bron- chial asthma and gender, and wheezing in the population aged 65 to 88 years was associated with a history of bronchial asthma and ischemic heart disease in a Japanese local community. In addition, a history of ischemic heart disease was associated with airway reversibility. Although it is well known that wheezing in elderly people contributes not only to bronchial asthma but also to acute heart failure at the primary care setting (15), it has been confirmed that a history of ischemic heart disease is an important cause of wheezing at the population-based setting.

Wheezing is often observed in patients with dyspnea due to heart failure (16). The mechanism of wheezing in heart failure is considered to be due to congestion of bronchial vessels, which leads to edema and thickening of bronchial wall (12). Furthermore, it has been reported that impaired left ventricular function can cause an abnormality of pulmonary function, such as airway hyper-responsiveness or restrictive and obstructive dysfunction (17). Hyperresponsiveness in patients with heart failure is considered to 
be mediated by distention of bronchial vessels with bronchial submucosal edema which is accentuated by methacholine, and the obstruction is partially corrected by the administration of bronchodilator (17).

In the present study, it was shown that a history of ischemic heart disease but not asthma was associated with airway reversibility. Witte et al reported that bronchodilators reverse the increased airway resistance in chronic heart failure (18). Thus it is possible that airway reversibility is correlated with heart function in participants with a history of ischemic heart disease. That is very important in the clinical setting. If a patient complains of wheezing and the pulmonary function test reveals airway reversibility, his or her diagnosis would be not only asthma but also cardiac disease, especially in the elderly. The rapid check of serum NTproBNP would be beneficial for the differential diagnosis between asthma and heart disease (19). On the other hand, we could not find a relationship between a history of asthma and airway reversibility. Among the 31 participants who had a history of asthma, 8 of them (27.6\%) had been taking asthma medication and 21 of them $(72.4 \%)$ had not been taking asthma medication at the survey time point. We consider that asthma medication may affect the relationship between a history of asthma and airway reversibility.

It has been reported that subjective symptoms, including wheezing, are related to QOL more closely than objective parameters, such as $\mathrm{FEV}_{1}$, in a population aged between 20 and 44 years (20). The authors of that study speculated that the underlying problem in the population was bronchial asthma. More recently, Voll-Aanerud et al reported that respiratory symptoms in adults were related to impaired QOL, regardless of diagnosis of asthma or COPD (21). Consistent with these studies, our results revealed that a lower QOL was not associated with impaired lung function but it was associated with wheezing in the study population.

In the present study, a history of allergic rhinitis was associated with wheezing in the univariate analysis. The frequent coexistence of asthma and allergic rhinitis has been reported (22), and allergic rhinitis is a risk factor for developing bronchial asthma $(23,24)$. However, it was rarely reported that allergic rhinitis was related to wheezing. Lee et al investigated the risk factors of wheezing in Korean military personnel. They reported that current wheeze was strongly associated with current allergic rhinoconjunctivitis (25). The present results also suggest that there would be a relationship between wheezing and rhinitis.

Because wheezing is a common clinical finding in patients with COPD, we expected that a higher proportion of wheezing participants would have COPD (26). One of the major criteria of COPD is post-bronchodilator airflow limitation (27). However, we did not find an association between wheezing and post-bronchodilator airflow limitation. Among our participants who met the lung function criteria of COPD, the mean (SD) $\mathrm{FEV}_{1} \%$ pred was $87.3 \%$ (18.8) (data not shown). That meant that most of them, even if they would have COPD, had relatively mild diseases, GOLD stage I or II (28). That may be the reason why we could not find an association between wheezing and postbronchodilator airflow limitation. On the other hand, the elder asthmatics might be complicated with COPD. As mentioned above, we did not differentiate the two diseases. However, we performed an airway reversibility test in 27 of 31 asthmatic participants. Only 3 of them showed postbronchodilator airway obstruction (COPD criteria). Those 3 participants showed mild postbronchodilator obstruction $\left(\mathrm{FEV}_{1} \%\right.$ pred $\left.>75 \%\right)$. Therefore, the effect of COPD on asthmatics in this study seemed to be minimal.

This study has some limitations. First, the survey was not distributed randomly but rather was given to individuals volunteering to participate. This may have introduced a bias into the study. However, the prevalence of wheezing and asthma in this study is not far from the results of our previous study in which the response rate was $78.9 \%$ (8). And the proportion of subjects aged 60 or over in this study was similar with that in the local population. Thus we believe that our findings can be generalized to the elderly in the community. Second, the diagnosis of asthma or ischemic heart disease was based on participants recall. That was not a complete diagnosis and there might be errors in some cases. To compensate for this possibility, we measured serum NT-proBNP levels. We detected the association between a history of ischemic heart disease and a high level of serum NT-proBNP. These findings might imply impaired heart function in participants with a history of ischemic heart disease. Third, most of the participants with suspected COPD from airflow limitation revealed relatively mild dysfunction as mentioned above. And the prevalence of participants who met COPD criteria of airflow limitation was lower than that of a previous Japanese survey (29). We must bear in mind the possibility that individuals with more severe COPD did not participate in this study.

\section{Conclusion}

Wheezing in the population aged 45 to 64 years was associated with bronchial asthma, and in the population aged 65 years and over, it was equally associated with both bronchial asthma and ischemic heart disease. Airway reversibility, which was present in $19.5 \%$ of our population, was associated with a history of ischemic heart disease. It is suggested that bronchial asthma and heart disease are both significant causes of wheezing and affect the QOL in the elderly of Japanese local community.

\section{The authors state that they have no Conflict of Interest (COI).}

\section{References}

1. Masoli M, Fabian D, Holt S, Beasley R. The global burden of asthma: executive summary of the GINA Dissemination Committee Report. Allergy 59: 469-478, 2004.

2. Suissa S, Ernst P, Benayoun S, et al. Low-dose inhaled corti- 
costeroids and the prevention of death. N Engl J Med 343: 332$336,2000$.

3. Lim S, Jatakanon A, John M, et al. Effect of inhaled budesonide on lung function and airway inflammation. Assessment by various inflammatory markers in mild asthma. Am J Respir Crit Care Med 159: 22-30, 1999.

4. Stupka E, deShazo R. Asthma in seniors: Part 1. Evidence for underdiagnosis, undertreatment, and increasing morbidity and mortality. Am J Med 122: 6-11, 2009.

5. Enright PL, McClelland RL, Newman AB, Gottlieb DJ, Lebowitz MD. Underdiagnosis and undertreatment of asthma in the elderly. Chest 116: 603-613, 1999.

6. Janson C, Anto J, Burney P, et al. The European Community Respiratory Health Survey: what are the main results so far? Eur Respir 18: 598-611, 2001.

7. Arif AA, Delclos GL, Lee ES, Tortolero SR, Whitehead LW. Prevalence and risk factors of asthma and wheezing among US adults: an analysis of the NHANES III data. Eur Respir J 21: 827833, 2003.

8. Fukutomi Y, Nakamura H, Kobayashi F, et al. Nationwide crosssectional population-based study on the prevalence of asthma and asthma symptoms among japanese adults. Int Arch Allergy Immunol 153: 280-287, 2010.

9. Hazell M, Frank T, Frank P. Health related quality of life in individuals with asthma related symptoms. Rspir Med 97: 1211-1218, 2003.

10. Braman SS, Davis SM. Wheezing in the elderly. Asthma and other causes. Clin Geriatr Med 2: 269-283, 1986.

11. Price DB, Yawn BP, Jones R. Improving the differential diagnosis of chronic obstructive pulmonary disease in primary care. Mayo Clin Proc 85: 1122-1129, 2010.

12. Faggiano P. Abnormalities of pulmonary function in congestive heart failure. Int J Cardiol 44: 1-8, 1994.

13. Ware JE. Improvements in short-form measures of health status: Introduction to a series. J Clin Epidemiol 61: 1-5, 2008.

14. Pellegrino R, Viegi G, Brusasco V, et al. Interpretative strategies for lung function tests. Eur Respir J 26: 948-968, 2005.

15. Jorge $\mathrm{S}$, Becquemin $\mathrm{MH}$, Delerme $\mathrm{S}$, et al. Cardiac asthma in eldely patients: incidence, clinical presentation and outcome. BMC Cardiovasc Disord 7: 16, 2007.

16. Oudejans I, Mosterd A, Bloemen JA, et al. Clinical evaluation of geriatric outpatients with suspected heart failure: value of symp- toms, signs, and additional tests. Eur J Heart Fail 13: 518-527, 2011.

17. Cabanes LR, Weber SN, Matran R, et al. Bronchial hyperresponsiveness to methacholine in patients with impaired left ventricular function. N Engl J Med 320: 1317-1322, 1989.

18. White K, Morice A, Cleland J, et al. The reversibility of increased airways resistance in chronic heart failure measured by impulse oscillometry. J Card Fail 10: 149-154, 2004.

19. McCullough PA, Hollander JE, Nowak RM, et al. Uncovering heart failure in patients with a history of pulmonary disease: Rationale for the early use of B-type natriuretic peptide in the emergency department. Acad Emerh Med 10: 198-204, 2003.

20. Matheson M, Raven J, Woods RK, et al. Wheeze not current asthma affects quality of life in young adults with asthma. Thorax 57: 165-167, 2002.

21. Voll-Aanerud M, Eagan T, Plana E, et al. Respiratory symptoms in adults are related to impaired quality of life, regardless of asthma and COPD: results from the European community respiratory health survey. Health Qaul Life Outcomes 8: 107, 2010.

22. Bousquet J, Vignola AM, Demoly P. Links between rhinitis and asthma. Allergy 58: 691-706, 2003.

23. van den Nieuwenhof $L$, Schermer T, Bosch Y, et al. Is physiciandiagnosed allergic rhinitis a risk factor for the development of asthma? Allergy 65: 1049-1055, 2010.

24. Shaaban R, Zureik M, Soussan D, et al. Rhinitis and onset of asthma: a longitudinal population-based study. Lancet 372: 10491057, 2008.

25. Lee SM, Ahn JS, Noh CS, Lee SW. Prevalence of allergic diseases and risk factors of wheezing in Korean military personnel. J Korean Med Sci 26: 201-206, 2011.

26. Bellia V, Battaglia S, Catalano F, et al. Aging and disability affect misdiagnosis of COPD in elderly asthmatics. Chest 123: 10661072, 2003.

27. Firdaus AA, Hesein M, Zanen P, Lammers J. Lower limit of normal or $\mathrm{FEV}_{1} / \mathrm{FVC}<0.70$ in diagnosing COPD: An evidence-based review. Respir Med 105: 907-915, 2011.

28. Rabe KF, Hurd S, Anzueto A, et al. Global strategy for the diagnosis, management, and prevention of chronic obstructive pulmonary disease: GOLD executive summary. Am J Respir Crit Care Med 176: 532-535, 2007.

29. Fukuchi $Y$, Nishimura M, Ichinose M. COPD in Japan: the Nippon COPD Epidemiology Study. Respirology 9: 458-465, 2004.

(C) 2011 The Japanese Society of Internal Medicine http://www.naika.or.jp/imindex.html 